\title{
Implicancias para la solución de controversias inversionista- Estado a raíz de la sentencia del caso Achmea ${ }^{1}$
}

\section{Implications for the resolution of investor-State disputes following the judgment of the Achmea case}

\author{
Pablo Nilo Donoso \\ pnilo@direcon.gob.cl \\ Licenciado en Ciencias Jurídicas y Sociales por la Universidad de Chile. Abogado. LL.M (Ruprecht-Karls- \\ Universität Heidelberg y Universidad de Chile). Ayudante Senior Derecho Internacional Público \\ (Universidad Diego Portales).
}

Resumen: En marzo de 2018, el Tribunal de Justicia de la Unión Europea (TJUE) resolvió que las cláusulas arbitrales para la solución de controversias entre inversionistas y Estados, establecidas en acuerdos bilaterales de inversión suscritos entre países miembros de la Unión, eran contrarias al derecho comunitario ${ }^{2}$. Este trabajo pretende presentar algunas de las repercusiones que esta decisión podría tener en el derecho internacional de las inversiones.

Palabras Clave: Solución de controversias inversionista-Estado, Tribunal de Justicia de la Unión Europea, derecho internacional de las inversiones, cuestiones prejudiciales, autonomía.

\begin{abstract}
In March 2018 the Court of Justice of the European Union (CJEU) ruled that the arbitration clauses for the settlement of disputes between investors and states, which had been established in bilateral investment treaties signed between member countries of the Union, were contrary to European law. This paper intends to present some of the repercussions that this decision could have on international investment law.
\end{abstract}

Key Words: Investor-State Dispute Settlement (ISDS), European Court of Justice, International Investment Law, Preliminary Ruling, Autonomy.

1 Artículo enviado el 06.09.2018 y aceptado el 20.11.2018.

2 Caso 284/16 República Eslovaca v. Achmea EU:C:2018:158. Disponible en http:// curia.europa.eu/juris/celex.jsf?celex $=62016$ CJ0284\&lang1=en\&type $=$ TXT\&ancre. $\quad$ El caso fue decidido por la Gran Sala el 6 de marzo de 2018.

Número de página no utilizable para citar 
Implicancias para la solución de controversias inversionista-Estado a raíz de la sentencia del caso Achmea Pablo Nilo Donoso

\section{Introducción}

En la sentencia del caso Achmea, la Corte Europea de Justicia estimó que las cláusulas arbitrales establecidas en Acuerdos para la Protección y Promoción de las Inversiones (APPIs) intra-europeos socavan el sistema de acciones legales establecido en el derecho de la Unión Europea (UE), amenazando la autonomía, efectividad, primacía y efecto directo del mismo, además del principio de confianza mutua entre los Estado miembros.

De esta forma, el efecto adverso que el arbitraje de inversiones en el marco de APPIs intraeuropeos puede tener en la autonomía, se manifestaría en que los tribunales arbitrales constituidos con base en estos acuerdos conocerían cuestiones de derecho de la UE eximiéndose del control del Tribunal Europeo de Justicia, al no ser competentes para plantear asuntos prejudiciales por medio del mecanismo establecido en el artículo $267^{3}$ del Tratado de Funcionamiento de la Unión Europea.

Esta decisión, de acuerdo con la interpretación de la Comisión Europea ${ }^{4}$, significa que los Estados miembros tienen la obligación de terminar los APPIs celebrados entre ellos, de acuerdo al principio de primacía del derecho europeo. Este último exige que los Estados tomen todas las medidas apropiadas a su disposición para erradicar las incompatibilidades que puedan presentarse con el orden legal de la UE.

El alcance de esta sentencia aún no ha sido definido con claridad, sin embargo, la incompatibilidad apreciada por el TJUE supone que las disposiciones sobre solución de

3 Artículo 267 del Tratado de Funcionamiento de la Unión Europea.- El Tribunal de Justicia de la Unión Europea será competente para pronunciarse, con carácter prejudicial:

a) sobre la interpretación de los Tratados;

b) sobre la validez e interpretación de los actos adoptados por las instituciones, órganos u organismos de la Unión;

Cuando se plantee una cuestión de esta naturaleza ante un órgano jurisdiccional de uno de los Estados miembros, dicho órgano podrá pedir al Tribunal que se pronuncie sobre la misma, si estima necesaria una decisión al respecto para poder emitir su fallo.

Cuando se plantee una cuestión de este tipo en un asunto pendiente ante un órgano jurisdiccional nacional, cuyas decisiones no sean susceptibles de ulterior recurso judicial de Derecho interno, dicho órgano estará obligado a someter la cuestión al Tribunal.

Cuando se plantee una cuestión de este tipo en un asunto pendiente ante un órgano jurisdiccional nacional en relación con una persona privada de libertad, el Tribunal de Justicia de la Unión Europea se pronunciará con la mayor brevedad.

(Énfasis del autor).

4 "The ruling] implies that all investor-State arbitration clauses in intra-EU BITS are inapplicable and that any arbitration tribunal established on the basis of such clauses lacks jurisdiction.... As a consequence, national courts are under the obligation to annul any arbitral award rendered on that basis and to refuse to enforce it.... Moreover.... [Member States] are bound to formally terminate their intra-EU BITs". Disponible en: https://ec.europa.eu/info/publications/180719communication-capital-movements_en [consulta 15.08.2018]

Número de página no utilizable para citar 
controversias inversionista-Estado establecidas en estos acuerdos son inaplicables y por lo tanto los tribunales arbitrales carecen de jurisdicción. La situación análoga se produce tratándose de la ejecución de laudos dictados por tribunales arbitrales constituidos de acuerdo a los APPIs.

A fin de dimensionar las consecuencias de esta decisión, deben observarse los distintos aspectos que componen la solución de controversias inversionista-Estado, tanto desde la perspectiva del inversionista que amparó su actividad en el marco de un APPI, y que a raíz de la decisión perdió la posibilidad de recurrir a arbitraje, como de aquellas partes en una controversia que sorpresivamente quedaron sin medios para ejecutar un laudo favorable.

Asimismo, es relevante que el lector tenga presente las características propias del arbitraje de inversión, especialmente la intención del inversionista de obtener una pronta solución a sus disputas, que el laudo sea dictado por especialistas en el área en que se suscita la controversia y que éstos actúen de forma independiente. De esta forma, uno de los elementos centrales del arbitraje de inversiones se relaciona con la necesidad de contar con individuos libres de influencias políticas, y con ofrecer al inversionista la posibilidad de defender sus intereses sin la necesidad de recurrir a la protección diplomática evitando la politización de las controversias.

El desarrollo de este trabajo se estructurará de la siguiente manera. En primer lugar, se tratarán los antecedentes del caso, concluyendo con un breve análisis de la sentencia del TJUE. A continuación, se analizarán sus implicancias en el derecho internacional de las inversiones y la manera en que este fallo presenta su argumentación basándose en disposiciones específicas de derecho europeo. Posteriormente, se examinarán las consecuencias derivadas de la Comunicación 547/2018 de 19 de julio de 2018, a través de la cual la Comisión Europea presentó al Parlamento y al Consejo Europeo su postura ante el caso Achmea, exponiendo asimismo las garantías que ofrece el derecho europeo para el libre flujo de inversiones dentro de la Unión. Finalmente, se presentarán conclusiones del análisis.

\section{Hechos esenciales del caso}

El año 2004, Eslovaquia abrió su mercado nacional a operadores privados de seguros de salud, escenario que impulsó a la compañía holandesa de seguros Achmea ${ }^{5}$ a establecer filiales en ese país. Sin embargo, entre los años 2006 y 2007 el gobierno eslovaco retrocedió parcialmente en la liberalización de su mercado de seguros, prohibiendo la distribución de dividendos a

5 En ese entonces, Eureko, pero para una mejor comprensión, se identificará al inversionista como Achmea.

Número de página no utilizable para citar 
Implicancias para la solución de controversias inversionista-Estado a raíz de la sentencia del caso Achmea Pablo Nilo Donoso

aseguradoras privadas. Esta prohibición fue revertida por el Tribunal Constitucional Eslovaco en 2011 y se promulgó una ley que permitía nuevamente la distribución de utilidades a esas entidades.

Utilizando como marco jurídico el Acuerdo para la Promoción y Protección de las Inversiones entre Países Bajos y Checoslovaquia de $1992^{6}$ (celebrado antes de la división entre Eslovaquia y República Checa, después de la cual, por sucesión de Estados, Eslovaquia pasaría a ser parte del acuerdo), Achmea demandó a Eslovaquia el año 2008. Este país invocó el artículo 8 del $\mathrm{APPI}^{7}$, que establece que corresponde al tribunal determinar la ley de fondo para su propio procedimiento, aplicando las reglas de la CNUDMI como ley arbitral. El tribunal eligió Frankfurt como sede, quedando el arbitraje sujeto a la ley alemana. En un primer momento ${ }^{8}$, Eslovaquia objetó la jurisdicción del tribunal arbitral, basándose en que tras su ingreso a la UE,

6 Para revisar el texto del acuerdo, ver: https://arbitrationlaw.com/sites/default/files/free_pdfs/netherlandsslovakia.pdf [consulta 12.07.2018]

7 Traducción del Artículo 8 del APPI Eslovaquia-Países Bajos:

1) Toda controversia entre una de las Partes contratantes y un inversor de la otra Parte contratante en relación con una inversión de este último debe dirimirse por acuerdo amistoso, siempre que sea posible.

2) Cada una de las Partes contratantes acepta, mediante el presente Tratado, que las controversias a que se refiere el apartado 1 del presente artículo se sometan a un tribunal arbitral en caso de que no se resuelvan por acuerdo amistoso en el plazo de seis meses desde la fecha en que una de las partes de la controversia haya solicitado un acuerdo amistoso al respecto.

3) El tribunal arbitral a que se refiere el apartado 2 del presente articulo se constituirá en cada caso del siguiente modo: cada una de las partes de la controversia designará un árbitro y los dos árbitros asi designados elegirán conjuntamente como tercer árbitro a un nacional de un tercer Estado, que será el presidente. Cada una de las partes de la controversia designará a su árbitro en el plazo de dos meses contado desde la fecha en la que el inversor notifique a la otra Parte contratante su intención de someter la controversia a un tribunal arbitral, y el presidente será designado en el plazo de tres meses contado desde la misma fecha.

4) Si en los plazos arriba mencionados no se produjeran las designaciones, cada una de las partes de la controversia podrá solicitar al Presidente del Instituto de Arbitraje de la Cámara de Comercio de Estocolmo que proceda a las designaciones necesarias. Si el presidente fuera nacional de una de las Partes contratantes o si se viera impedido de ejercer dicha función por cualquier otro motivo, se solicitará al vicepresidente que proceda a las designaciones necesarias. Si el vicepresidente fuera nacional de una de las Partes contratantes o si también se viera impedido de ejercer dicha función, se solicitará al miembro de más edad del Instituto de Arbitraje que no tenga la nacionalidad de ninguna de las Partes contratantes que proceda a las designaciones necesarias.

5) El tribunal arbitral determinará su propio procedimiento aplicando el Reglamento de Arbitraje de la Comisión de las Naciones Unidas para el Derecho Mercantil Internacional (CNUDMI).

6) El tribunal arbitral resolverá con arreglo a Derecho, teniendo en cuenta, en particular, pero no exclusivamente:

- el Derecho en vigor de la Parte contratante afectada;

- las disposiciones del presente Tratado y cualquier otro tratado pertinente entre las Partes contratantes;

- las disposiciones de tratados especiales relativos a la inversión;

- los principios generales del Derecho internacional.

7) El tribunal resolverá por mayoría de votos; su decisión será definitiva y obligatoria para las partes de la controversia.

(Énfasis del autor).

8 Estas objeciones se presentaron el 30 de octubre de 2009. Ver párrafo 19 del Caso ante la CPA No. 2008-13. Eureko B.V contra la República Eslovaca, Award on Jurisdiction, Arbitrability and Suspension, 26 de octubre de 2010. Disponible en: https://www.italaw.com/sites/default/files/case-documents/ita0309.pdf [consulta 13.07.2018]

Número de página no utilizable para citar 
el artículo 8 del APPI, que permitía recurrir a arbitraje, sería incompatible con el derecho de la Unión, considerando que la adhesión habría supuesto la terminación implícita del APPI. Por medio de un laudo interlocutorio de octubre de 2010' el tribunal arbitral rechazó estos argumentos y en diciembre de 2012, el laudo definitivo condenó a Eslovaquia a indemnizar a Achmea por la suma de 22.1 millones de euros más costas y gastos de representación legal ${ }^{10}$. Debe tenerse presente que en dicho laudo no se hizo referencia al derecho de la UE.

Tras esta decisión, Eslovaquia intentó sin éxito anular el laudo, de acuerdo con lo previsto en el artículo 1059 del Código de Procedimiento Civil alemán ${ }^{11}$. Como último recurso, apeló ante el Bundesgerichtshof alemán (equivalente a la Corte Suprema en Chile), quien no se mostró proclive a aceptar el argumento de la incompatibilidad de las disposiciones del APPI, relativas a la posibilidad de recurrir a arbitraje, con el derecho de la UE. Sin embargo, en vista de las potenciales consecuencias de su decisión, el Bundesgerichtshof alemán dirigió una consulta preliminar al Tribunal de Justicia de la UE sobre la interpretación de los artículos $18^{12}, 267^{13} \mathrm{y}$ $344^{14}$ de su Tratado de Funcionamiento (TFUE), con el fin de determinar si la disposición del APPI que permite a un inversionista de una parte contratante recurrir a un tribunal arbitral, era incompatible con esas disposiciones.

\section{Sentencia del Tribunal Europeo de Justicia}

Consciente de las implicancias políticas de esta consulta preliminar, el tribunal decidió someter la decisión a la Gran Sala ${ }^{15}$. Tras escuchar la opinión del Abogado General ${ }^{16}$, quien se

9 Disponible en https://www.italaw.com/sites/default/files/case-documents/ita0309.pdf [consulta 12.07.2018]

10 Disponible en https://www.italaw.com/sites/default/files/case-documents/italaw3206.pdf [consulta 12.07.2018]

11 Versión original https://dejure.org/gesetze/ZPO/1059.html [consulta 12.07.2018]

12 Artículo 18 del Tratado de Funcionamiento de la Unión Europea.- En el ámbito de aplicación de los Tratados, y sin perjuicio de las disposiciones particulares previstas en los mismos, se probibirá toda discriminación por razón de la nacionalidad.

El Parlamento Europeo y el Consejo, con arreglo al procedimiento legislativo ordinario, podrán establecer la regulación necesaria para probibir dichas discriminaciones.

13 Ver supra nota 2.

14 Artículo 344 del Tratado de Funcionamiento de la Unión Europea.- Los Estados miembros se comprometen a no someter las controversias relativas a la interpretación o aplicación de los Tratados a un procedimiento de solución distinto de los previstos en los mismos.

15 El inciso final del Artículo 16 del Tratado de Funcionamiento de la Unión Europea establece que: [...] Asimismo, cuando considere que un asunto del que conoce reviste una importancia excepcional, el Tribunal de Justicia podrá decidir, oído el Abogado General, su atribución al Pleno.

16 El Abogado General es un actor determinante para el desarrollo del Derecho europeo. Integrado en el Tribunal de Justicia de la Unión Europea como un miembro más entre los magistrados, sus conclusiones no son vinculantes, pero ejercen influencia sobre la comunidad jurídica de la Unión. 
Implicancias para la solución de controversias inversionista-Estado a raíz de la sentencia del caso Achmea Pablo Nilo Donoso

pronunció en favor de la legalidad del arbitraje de inversiones, no vislumbrando incompatibilidad entre el recurso a arbitraje y las disposiciones señaladas, el TJUE pronunció su sentencia ${ }^{17}$.

A diferencia de la opinión del Abogado General, la Gran Sala decidió que la cláusula arbitral del APPI entre Eslovaquia y los Países Bajos era incompatible con los artículos 344 y 267 del Tratado de Funcionamiento de la UE, siendo el "acuerdo arbitral" bajo el artículo 8 del APPI contrario al derecho de la UE. En otras palabras, el tribunal estableció que el arbitraje de inversiones amparado en los Acuerdos Bilaterales de Inversiones intra-europeos no era compatible con el derecho de la UE; esto sería así, por las siguientes razones:

1) Por la autonomía del derecho de la UE en el orden europeo;

2) Por la posibilidad de que el tribunal arbitral sea llamado a interpretar o aplicar el derecho de la UE;

3) Porque el tribunal arbitral no constituye un tribunal o un órgano jurisdiccional de un Estado miembro, por lo que no puede someter una cuestión prejudicial al Tribunal Europeo de Justicia y, finalmente;

4) Porque el laudo arbitral no es susceptible de revisión por una corte de un Estado miembro para asegurar su compatibilidad con el derecho de la UE.

Es importante resaltar que una interpretación expansiva de la sentencia indicaría que ésta no sólo se pronuncia sobre arbitraje de inversiones, sino que también sobre regímenes futuros de

El artículo 252 del TFUE señala que: El Tribunal de Justicia estará asistido por ocho abogados generales. Si el Tribunal de Justicia lo solicitare, el Consejo, por unanimidad, podrá aumentar el número de abogados generales.

La función del abogado general consistirá en presentar públicamente, con toda imparcialidad e independencia, conclusiones motivadas sobre los asuntos que, de conformidad con el Estatuto del Tribunal de Justicia de la Unión Europea, requieran su intervención.

17 Conclusión del Abogado General: "Los artículos 18 TFUE, 267 TFUE y 344 TFUE deben interpretarse en el sentido de que no obstan a la aplicación de un mecanismo de resolución de controversias entre un inversor y un Estado establecido en un acuerdo bilateral de inversión celebrado antes de la adhesión a la Unión Europea de uno de los Estados contratantes y que prevé que un inversor de un Estado contratante pueda, en caso de litigio sobre inversiones en el otro Estado contratante, entablar un procedimiento contra este último Estado ante un tribunal arbitral." (párrafo 273 de las conclusiones del Abogado General Sr. Melchior Wathelet presentadas el 19 de septiembre de 2017 (1) en el Asunto C- 284/16 República Eslovaca Achmea BV.) Disponible en: http:/ / curia.europa.eu/juris/document/document.jsf;jsessionid=9ea7d0f130dafc2b8ef47c7e42c5a71c825cfe2 dc46f.e34KaxiLc3eQc40LaxqMbN4Pb3qKe0?text=\&docid=194583\&pageIndex=0\&doclang=ES\&mode=re $\mathrm{q} \& \operatorname{dir}=\&$ occ $=$ first\&part $=1 \& \mathrm{cid}=752071[$ consulta 13.07.2018]

Esta conclusión implica que el derecho de la UE no impide la aplicación de un mecanismo de solución de controversias inversionista-Estado en un acuerdo bilateral de inversiones entre dos Estados miembros.

Número de página no utilizable para citar 
solución de controversias en derecho internacional público y su relación con la función adjudicativa del Tribunal Europeo de Justicia ${ }^{18}$.

Esta decisión es sorpresiva, puesto que pone en jaque el mecanismo de solución de controversias y genera incertidumbre respecto de los inversionistas y Estados que se encuentran en el marco de una disputa por violaciones a un acuerdo bilateral de inversiones intra-europeo. Del mismo modo, la decisión impone dificultades para la ejecución de los laudos derivados de tales acuerdos, puesto que deberán recurrir a jurisdicciones y recursos situados fuera de la UE para su cumplimiento. Así, la incertidumbre que plantea esta decisión hace que el sistema tal como fue planteado pierda eficacia y en el corto y mediano plazo boicotee la seguridad jurídica que pretende amparar.

\section{Implicancias de la sentencia en el caso Achmea}

El fallo se refiere esencialmente a la autonomía del derecho de la Unión Europea ${ }^{19}$, y con base en ésta el tribunal establece que las cláusulas arbitrales entre Estados miembros vulnerarían dicho principio. De esta forma, el tribunal cierra toda posibilidad a la continuidad de la vigencia de los APPIs celebrados entre Estados de la Unión, cuya terminación había sido solicitada anteriormente por la Comisión Europea en junio de $2015^{20}$. Así, la decisión debe ser entendida en el contexto comunitario en el que se emite, considerando los esfuerzos que ha desplegado la Comisión Europea para que los Estados miembros pongan término a sus APPIs (Binder y Hofbauer, 2017: 179) y su oposición al arbitraje inversionista-Estado en virtud de esos acuerdos.

En el fallo, el TJUE presenta su visión sobre los tribunales de inversión y confirma que estos no son parte del sistema legal de la UE. Es más, ve en ellos una amenaza latente a la autonomía de su derecho. De este modo, al sustraerse las controversias de inversiones de los tribunales nacionales a través de cláusulas arbitrales, se impide la aplicación del sistema recursivo que evalúa la compatibilidad de las decisiones de tribunales nacionales con el derecho comunitario. Esta sustracción generaría asimismo inconvenientes con disposiciones del Tratado de la Unión Europea $^{21}$, ya que acuerdo con lo estipulado en el artículo 19 de dicho cuerpo legal, "[1]os Estados miembros establecerán las vías de recurso necesarias para garantizar la tutela judicial

18 Ver en este sentido, párrafo 58 de la sentencia del caso Achmea.

19 Ver párrafo 59 de la sentencia del caso Achmea.

20 Para acceder al comunicado de prensa, ver http://europa.eu/rapid/press-release_IP-15-5198_en.pdf [consulta 12.07.2018]

21 Tratado de la Unión Europea de 7 de febrero de 1992 firmado en Maastricht. 
Implicancias para la solución de controversias inversionista-Estado a raíz de la sentencia del caso Achmea Pablo Nilo Donoso

efectiva en los ámbitos cubiertos por el Derecho de la Unión”. Así, al remitir la controversia a un tribunal ajeno al poder judicial de los Estados miembros, se estaría incumpliendo con esta garantía.

Análogamente, los laudos dictados por tribunales CIADI también se verían afectados, toda vez que la ejecución sobre bienes situados en la UE, implicaría aplicar el derecho de los acuerdos (constatado como incompatible por el TJUE) en las jurisdicciones nacionales, vulnerando lo prescrito en el artículo 351 del $\mathrm{TFUE}^{22}$. Es de esperar que ciertos Estados miembros y sus inversionistas intentarán reducir estos efectos, de modo tal que las cláusulas de otros acuerdos, que no sean análogas al artículo 8 del APPI suscrito entre los Países Bajos y Eslovaquia, no se vean afectadas por esta decisión.

La sentencia del caso Achmea implica, por tanto, un respaldo a la solicitud de la Comisión Europea de poner término a los APPIs intra-europeos (en septiembre de 2016, la Comisión había iniciado procedimientos de incumplimiento contra ciertos Estados miembros por no terminar sus $\mathrm{APPIs}^{23}$ ), ratificando su posición presentada como amicus curiae en el caso Achmea $^{24}$ y marcando la pauta para futuros casos en que se produzca ese conflicto normativo.

22 El inciso $2^{\circ}$ del Artículo 351, señala en relación a los derecho y obligaciones que resulten de convenios celebrados entre Estados con anterioridad a la fecha de su adhesión: "en la medida en que tales convenios sean incompatibles con los Tratados, el Estado o los Estados miembros de que se trate recurrirán a todos los medios apropiados para eliminar las incompatibilidades que se hayan observado. En caso necesario, los Estados miembros se prestarán ayuda mutua para lograr tal finalidad y adoptarán, en su caso, una postura común."

23 Con fecha 29 de septiembre de 2016, mediante un comunicado de prensa, se expuso lo siguiente: "La Comisión Europea ha pedido hoy formalmente a Austria, los Países Bajos, Rumanía, Eslovaquia y Suecia que rescindan sus convenios bilaterales de inversión («CBI») intra-UE. Los CBI son convenios que establecen las condiciones de la inversión privada de los nacionales y las empresas de un país en otro. Muchos de estos CBI intra-UE se celebraron en la década de los noventa. Se celebraron sobre todo entre los Estados miembros de la UE existentes y los que formarían la «EU-12», los Estados miembros que se adhirieron en 2004 y 2007. Su objetivo era tranquilizar a los inversores en un momento en que los inversores privados, a menudo por razones históricas y políticas, podrían haber tenido dudas a la hora de invertir en dichos países. Desde la ampliación, estas garantías adicionales no deberían ser necesarias, ya que las normas de la UE sobre el mercado único, tales como las relativas a la libertad de establecimiento y a la libre circulación de capitales, ya ofrecen un marco jurídico para las inversiones transfronterizas. Todos los Estados miembros están sujetos a las mismas normas de la UE, que también protegen a los inversores de la UE." Ver: http://europa.eu/rapid/press-release_MEMO-16-3125_es.htm?locale=EN. [consulta 13.08.201]

24 "There are some provisions of the Dutch-Slovak BIT that raise fundamental questions regarding compatibility with EU law. Most prominent among these are the provisions of the BIT providing for an investor-State arbitral mechanism (set out in Art. 8), and the provisions of the BIT providing for an inter-State arbitral mechanism (set out in Art. 10). These provisions conflict with EU law on the exclusive competence of the EU court $[\mathrm{s}]$ for claims which involve EU law, even for claims where EU law would only partially be affected. The European Commission must therefore [...] express its reservation with respect to the Arbitral Tribunal's competence to arbitrate the claim brought before it by Eureko B.V”. Amicus Curiae presentado por la Comisión Europea, citado por el tribunal arbitral en el caso Achmea B.V. v. República Eslovaca, UNCITRAL, CPA Caso No. 2008-13 (Laudo de Jurisdicción 7 de diciembre de 2012), para. 193

Número de página no utilizable para citar 
Una de las posibles formas de terminar con estos acuerdos sería a través de un tratado internacional en el que los Estados miembros de la UE acuerden tal objeto para todos los APPIs vigentes entre ellos sin la aplicación de una cláusula de supervivencia. Sin embargo, y pese a las normas existentes en el derecho de la UE que brindan protección a las inversiones transfronterizas, la realidad es que la relativa carencia de disposiciones sustantivas (y aún más, procedimentales) propias del derecho de las inversiones podría generar un vacío con repercusiones en la protección de los inversionistas europeos. Esta insuficiencia podría suplirse con una regulación exhaustiva en la materia que otorgue mayor seguridad jurídica, a la cual los Estados pudiesen adherir de forma similar a la modalidad opt-in presentada en la Convención de Mauricio ${ }^{25}$.

Adicionalmente, queda en suspenso qué ocurrirá con los arbitrajes pendientes de resolución respecto a su reconocimiento y posible ejecución ${ }^{26}$, los que podrán verse afectados en este nuevo escenario. Si bien el Tribunal Europeo de Justicia no podría directamente invalidar el APPI entre Eslovaquia y los Países Bajos, el derecho de la UE exige a los tribunales nacionales que anulen y excluyan la aplicación de legislación nacional e internacional que sea incompatible con el derecho europeo. Esto significa que la ejecución de laudos derivados de tribunales arbitrales constituidos conforme a APPIs celebrados entre miembros de la UE se ha vuelto extremadamente difícil. En este sentido, es interesante revisar el caso de España, que, a raíz de los recortes a las ayudas a las energías renovables, enfrenta alrededor de 30 arbitrajes con montos demandados superiores a los 7.500 millones de euros ${ }^{27}$. La decisión en Achmea ha permitido hasta ahora, en al menos un $\operatorname{caso}^{28}$, suspender provisionalmente la ejecución del laudo que condenaba a España al pago de indemnizaciones por daños a inversionistas europeos (Dahlquist, 2018) ${ }^{29}$.

La sentencia del caso Achmea marca también, un paso obligatorio hacia la terminación de los acuerdos bilaterales de inversión que proliferaron tras la caída del muro de Berlín $^{30}$ y que

Para mayor información en relación con los antecedentes de la consulta de Bélgica al TJUE, ver Ankersmit (2016).

25 Convención de las Naciones Unidas sobre la Transparencia en los Arbitrajes entre Inversionistas y Estados en el Marco de un Tratado. Ver: http://www.uncitral.org/uncitral/es/uncitral_texts/arbitration/2014Transparency_Convention.html [consulta 13.08.2018]

26 Ver análisis en relación con laudos que no podrían ejecutarse como consecuencia de la sentencia del caso Achmea en CIEL (2018: 5).

27 Ver https://www.eldiario.es/economia/Gobierno-millones-arbitrajes-recortes-renovables_0_705880371.html [consulta 12.07.2018]

28 Ver http://www.europapress.es/economia/energia-00341/noticia-tribunal-suecia-suspende-ejecucion-laudonovenergia-contra-espana-recorte-renovables-20180517195808.html [consulta 12.07.2018]

29 Ver en este sentido, Dahlquist (2018).

30 Ver en este sentido el análisis de Alschner (2013: 475) y Hallward-Driemeier (2003: 9). 
Implicancias para la solución de controversias inversionista-Estado a raíz de la sentencia del caso Achmea Pablo Nilo Donoso

impusieron obligaciones (que algunos análisis estimaron inequitativas ${ }^{31}$ ) a los Estados receptores de inversión (principalmente del este), y que hoy en día son miembros de la $\mathrm{UE}^{32}$.

Finalmente, este fallo también da una señal clara a los inversionistas europeos, en el sentido que ya no corresponde esperar obtener una posición jurídica más favorable que la que podrían aspirar en su propio Estado en aplicación de la legislación europea. En este sentido la comunicación descrita a continuación intenta probar que los tratados bilaterales de inversión suscritos entre miembros de la UE no serían necesarios, puesto que el derecho de la Unión otorgaría una protección comprensiva a los inversionistas.

\section{Comunicación de la Comisión al Parlamento y al Consejo Europeo}

El 19 de julio de 2018, la Comisión Europea remitió una comunicación dirigida al Parlamento y al Consejo europeo, titulada "Protection of intra-EU investment". Dicha comunicación plantea ciertos conflictos que se presentan como consecuencia de APPIs celebrados entre Estados de la UE y Estados que no formaban parte de ésta al momento de la suscripción de dichos acuerdos, pero que adhirieron a la Unión con posterioridad. Como resultado de estas accesiones, las disposiciones sustantivas de los APPIs, al pasar a ser aplicadas entre Estados miembros, dieron lugar a un sistema paralelo a la legislación de la UE, superponiéndose a estas reglas y restringiendo la aplicación del derecho de la UE.

En relación con el caso Achmea y sus consecuencias, la Comisión Europea señaló que el recurrir a cláusulas arbitrales establecidas en acuerdos intra-UE menoscaba el mecanismo establecido en el artículo 267 del Tratado de Funcionamiento de la Unión Europea ${ }^{33}$ presentándose una incompatibilidad con el principio de cooperación leal. Lo anterior implica que todas las cláusulas arbitrales que establezcan el mecanismo de solución de controversias inversionista-Estado en APPIs intra-europeos son inaplicables y que cualquier tribunal arbitral

31 Ver comentarios de Matei (2015) en relación con los casos Micula v Romania, Caso CIADI No. ARB/05/20; Eastern Sugar Netherlands v CzechRepublic, Caso CCE No. 088/2004; y Eureko Netherlands v Slovak Republic, CNUDMI, Caso CPA No. 2008-13.

Recientemente se ha indagado en relación al objetivo de los APPIs y si este era realmente la promoción de las inversiones. Al respecto, ver el comentario de St. John (2018). En sentido contrario, se ha argumentado que estos acuerdos sí incrementarían los flujos de inversión (Lejour y Salfi, 2015).

32 Para conocer los elementos de este debate, veáse Olivet (2013). En el mismo sentido Hobér (2015), para una breve apreciación de las consecuencias en relación con los APPIs celebrados con Estados que posteriormente fueron parte de la Unión Europea.

33 Ver supra nota 2. 
establecido de acuerdo a dichas cláusulas carece de jurisdicción debido a la ausencia de un acuerdo arbitral válido. En consecuencia, los tribunales nacionales se encuentran bajo la obligación de anular y negar la ejecución de cualquier laudo que haya sido dictado sobre esa base. Los Estados miembros que sean parte de casos pendientes deben asimismo responder a las consecuencias que se deriven del fallo. Además, de conformidad con el principio de seguridad jurídica, están obligados a poner formalmente término a los APPIs intra-europeos que hayan suscrito.

Según la Comisión, esta consecuencia también es replicable a la Carta de Energía respecto de las relaciones intra-UE ${ }^{34}$, en la medida que al igual que las cláusulas de APPIs de tales características, la aplicación de una cláusula arbitral como la dispuesta en el artículo 26 de la Carta de Energía, que establece un mecanismo inversionista-Estado, abriría la posibilidad de llevar esas disputas a un órgano que no es parte del sistema judicial de la UE. Excede este trabajo el análisis de los conflictos normativos derivados de la conclusión a la que llegó la Comisión Europea respecto de las implicancias del fallo Achmea en la Carta de Energía. Sin embargo, es necesario señalar que la idea de que los Estados europeos busquen hacer inaplicable el mecanismo de solución de controversias que prevé el tratado, con el objeto de que el TJEU resuelva las disputas que se susciten entre ellos en el marco de la Carta de Energía, parece a primera vista ser una solución poco realista, por cuanto implicaría una reserva (prohibidas por el artículo 46 del Tratado) y que de todas maneras difícilmente sería aceptada por los demás Estados ajenos a la UE sin requerir concesiones que mejoren su posición relativa dentro del acuerdo (el artículo 42 de la Carta de Energía establece que cualquier modificación al tratado requiere el consentimiento de al menos tres cuartas partes de los Estados parte y los miembros de la UE representan tan sólo el 54\% del total) ${ }^{35}$.

La comunicación continúa explicando a grandes rasgos el sistema europeo de protección de las inversiones transfronterizas desde el establecimiento hasta el fin de la inversión, describiendo

34 Este argumento ha sido planteado por la Comisión Europea en distintos casos, siendo rechazado en varias ocasiones, por ejemplo: Charanne v. España, Caso Cámara de Comercio de Estocolmo (CCE) No. V062/2012 (21.01.2016); REEF v. España, Caso CIADI No. ARB/13/30 (6.06.2016); Isolux v. España, Caso CCE No. V2013/153 (17.07.2016); Blusun v. Italia, Caso CIADI No. ARB/14/3 (27.12.2016); Eiser Infrastructure $v$. España, Caso CIADI No. ARB/13/36 (4.05.2017).

En este sentido, previo a la dictación del fallo de Achmea, la relación entre la UE, sus miembros y la Carta de Energía podía resumirse de la siguiente forma: Primero, la Carta de Energía (y en particular la disposición sobre solución de controversias inversionista-Estado) corresponde a un "acuerdo mixto", es decir, abarca un tema sobre el que la UE sólo goza de competencia compartida junto con sus Estados miembros. En segundo lugar, de acuerdo con la práctica de la UE, cuando se ha pretendido hacer prevalecer la legislación europea sobre las disposiciones de los tratados en acuerdos mixtos, se ha agregado una "cláusula de desconexión" estableciendo esta situación. En tercer lugar, no existe una cláusula de desconexión en la Carta de Energía. En cuarto lugar, los tribunales arbitrales han rechazado unánimemente el argumento de la Comisión Europea en virtud del cual la cláusula arbitral de la Carta de Energía no puede servir de base para procedimientos arbitrales inversionista-Estado intra-UE. Traducción del autor (Leikin y Magnarelli, 2017)

35 Para mayor información respecto a la denuncia de ciertos Estados de este tratado, ver Voon y Mitchell (2017); asimismo, ver Iacob y Cirling (2016). 
la protección existente contra actos arbitrarios, el principio de no discriminación y las consecuencias de su aplicación. Asimismo, se refiere a los principios de derecho europeo y a los derechos fundamentales como límites a posibles restricciones.

A continuación, trata sobre el cumplimiento de los derechos de los inversionistas y a la efectiva protección judicial que les otorga el derecho de la UE. En este contexto, enfatiza el rol de la remisión que las cortes nacionales de los Estados miembros pueden hacer al TJUE, cuando se trate de consultas sobre la interpretación de la legislación comunitaria que sean necesarias para resolver asuntos que se ventilen bajo su jurisdicción, a fin de evitar contradicciones con el ordenamiento jurídico europeo.

Con base en este análisis, la Comisión agrega que estas cuestiones preliminares pueden referirse a la validez de la normativa de la UE, en cuyo caso, si se trata de asuntos relevantes, los tribunales nacionales deberán remitirlo a la Corte Europea de Justicia, quien tiene la competencia exclusiva en la revisión de la validez de los actos de la UE.

Es en este sentido que la Comisión sostiene que a efectos de calificar como "corte o tribunal de un Estado miembro", y así poder realizar la remisión al Tribunal Europeo de Justicia de acuerdo al artículo 267 del TFUE, el órgano en cuestión debe cumplir una serie de requisitos (entre otros, si se encuentra establecido por ley, si es permanente, si su jurisdicción es obligatoria, o si su procedimiento es aplicable inter partes, si aplica reglas de derecho y si es independiente $\left.{ }^{36}\right)$. De este modo, la Comisión concluye que los árbitros y los tribunales arbitrales establecidos en los APPIs intra-europeos, no cumplen estos requisitos y por lo tanto no pueden ser considerados cortes o tribunales de acuerdo al artículo 267 de TFUE.

Así, de acuerdo al mandato del artículo 17 (1) del Tratado de la UE, que le confiere a la Comisión la responsabilidad de la aplicación, implementación y cumplimiento efectivo del derecho de la UE, esta puede revisar medidas y asegurar su adecuación con las garantías de protección a los inversionistas. En consecuencia, el objetivo principal del procedimiento del artículo 267 TFUE señalado en el párrafo anterior es asegurar que las acciones u omisiones de los Estados miembros se ajusten al derecho de la UE.

En particular, es relevante para este análisis la mención que realiza la Comisión sobre la aplicación efectiva del derecho de la UE que las autoridades administrativas nacionales deben

36 Ver C-54/96 Dorsch Consult, ECLI:EU:C:1997:413, para. 23: "Para apreciar si el organismo remitente posee el carácter de un órgano jurisdiccional en el sentido del artículo 177 del Tratado, cuestión que pertenece únicamente al ámbito del Derecho comunitario, el Tribunal de Justicia tiene en cuenta un conjunto de elementos, como son el origen legal del órgano, su permanencia, el carácter obligatorio de su jurisdicción, el carácter contradictorio del procedimiento, la aplicación por parte del órgano de normas jurídicas, así como su independencia." Disponible en: https://eur-lex.europa.eu/legalcontent/ES/TXT/PDF/?uri=CELEX:61996CJ0054\&from=EN [consulta 15.08.2018] 
llevar a cabo, interpretando la ley nacional de acuerdo con la legislación europea, derogando la normativa nacional que sea contraria a la ley de la UE y subsanando las consecuencias que puedan derivarse de violaciones al derecho de la UE. Estos principios se desprenden del deber de "cooperación sincera" de los Estados miembros, establecido en el artículo 4 (3) del TFUE, y de la primacía del derecho de la UE. En consonancia, estos elementos permiten la adecuada y efectiva aplicación de las garantías dispuestas en el sistema europeo, sin necesidad de recurrir a medios judiciales. En razón de lo anterior, ambos preceptos deben ser obedecidos, incluso si el procedimiento nacional no los establece expresamente.

De esta forma, la Comisión concluye que los inversionistas de la UE no pueden invocar los APPIs concluidos entre Estados miembros para hacer valer sus pretensiones ante posibles vulneraciones de derechos, ya que el sistema de solución de controversias inversionista-Estado planteado en estos acuerdos (como así también los tribunales arbitrales que se constituyan al alero de la Carta de Energía), son incompatibles con el derecho de la UE. Como alternativa, la Comisión incentiva la utilización del sistema legal de la UE, en vista que este ofrecería una adecuada y efectiva protección a las inversiones transfronterizas que realicen los inversionistas miembros de la UE.

\section{Conclusiones}

La decisión en Achmea plantea diversas consecuencias para el arbitraje de inversiones.

Primero. Al fallar en el sentido opuesto al planteado por el Abogado General y a lo esperado por el Bundesgerichtshof al remitir su consulta con base en el Artículo 267 (3) del TFUE (ambos confiando que el arbitraje de inversiones intra-europeo fuera compatible con el derecho de la Unión), la Gran Sala del TJUE hace evidente que sostiene su argumentación sobre una de las decisiones más políticas de la Corte en relación con la autonomía del ordenamiento jurídico europeo (el Dictamen 2/13). Utilizando dicha decisión como telón de fondo, reafirma su carácter de último bastión interpretativo del derecho de la Unión. Tomando en cuenta el contexto político en que esta decisión es dictada, es dable interpretar que el máximo tribunal europeo buscó establecer los límites legalmente permisibles para la solución de controversias, no sólo respecto de los APPIs intra-europeos, sino también en relación con la cláusula arbitral de la Carta de Energía (la que al igual que estos últimos, permite sustraer de la jurisdicción de las cortes nacionales controversias en materia de inversiones en el sector energético suscitadas entre países miembros de la Unión). Asimismo, se desprenden consecuencias respecto del acuerdo de retirada de la UE en el contexto del Brexit. En este sentido, la decisión en Achmea 
permite a los negociadores del acuerdo de retirada poder determinar hasta qué punto el TJUE está dispuesto a llegar para proteger la autonomía del derecho europeo y, a grandes rasgos, cuándo esta autonomía se vería vulnerada ${ }^{37}$. Teniendo en cuenta la incertidumbre que rodea al Brexit (si habrá o no acuerdo, el período de transición y si efectivamente el Reino Unido se retirará de la UE), la decisión en Achmea presenta implicancia respecto al futuro de las inversiones en esa jurisdicción. Si se adopta el acuerdo de retirada, las decisiones del TJUE continuarán aplicándose al Reino Unido hasta terminado el período de transición de 21 meses. En caso contrario, si el Parlamento no aprueba el acuerdo de retirada, no habrá un período de transición y el derecho y las decisiones de la UE no será vinculantes para el Reino Unido. De esta forma, es posible que las compañías europeas que busquen invertir en países de la UE con los que el Reino Unido tiene APPIs comiencen a estructurar sus inversiones a través de subsidiarias en el Reino Unido, con el fin de beneficiarse de la protección otorgada por dichos acuerdos bilaterales, sin la supervigilancia del TJUE.

Segundo. Si bien los inversionistas europeos se han visto favorecidos por el régimen de inversiones creado por los APPIs intra-europeos, esta red de acuerdos no fue creada con la finalidad de sustraer las controversias hacia un foro más conveniente que el derecho de la UE, puesto que todos los acuerdos fueron suscritos con Estados que en ese momento no eran parte de la Unión Europea, y que posteriormente, negociaron su adhesión a este régimen común. De esta forma, el fallo cierra el debate en el sentido que fija nuevos parámetros para los inversionistas europeos al señalarles que no podrán sujetarse a un régimen más favorable que aquél que podrían optar en su propio Estado, como miembro de la UE. Coincidentemente, el TJUE al concluir que "un tribunal arbitral como el establecido en el artículo 8 del TBI no puede calificarse de «órgano jurisdiccional de uno de los Estados miembros» en el sentido del artículo 267 del TFUE y no est[ando] por tanto facultado para solicitar una decisión prejudicial al Tribunal de Justicia" ${ }^{38}$, reconoce la naturaleza excepcional del mismo respecto al derecho nacional, que le impide someter sus resoluciones "a mecanismos que permitan asegurar la plena eficacia de las normas de la Unión"39

Tercero. La Comisión fue cauta al limitar (en la referida comunicación) los alcances del fallo en el caso Achmea sólo a los Estados miembros, sin embargo, es con base en disposiciones tales como al artículo 351 del Tratado de Funcionamiento de la Unión Europea, que podrían presentarse posibles incompatibilidades en relación con las obligaciones derivadas del

37 Ver en este sentido el artículo 163 del proyecto de acuerdo de retirada del Reino Unido de Gran Bretaña e Irlanda del Norte de la Unión Europea y la Comunidad Europea de Energía Atómica: https://ec.europa.eu/commission/sites/beta-political/files/draft_agreement_coloured.pdf] [consulta 14.08.2018]. Sin perjuicio de lo señalado, es esperable que la Opinión 1/17, prevista para inicios de 2019, provea mayor precisión en relación al Brexit.

38 Sentencia del Tribunal de Justicia de la UE en el caso Achmea, para. 49.

39 Ver Sentencia del Tribunal de Justicia de la UE en el caso Achmea, para. 43. 
Convenio CIADI respecto de Estados foráneos a la Unión, tanto por la posible aplicación del derecho de la UE a sus controversias con Estados miembros, como en lo relativo a la ejecución de los laudos. En el mismo sentido, el razonamiento del TJUE impediría que los tribunales internacionales conozcan de asuntos propios del derecho de la UE, ya que el conflicto normativo que se presentaría tendría repercusiones análogas sobre la autonomía de la legislación europea. La respuesta a dicha compatibilidad seguramente será resuelta cuando el TJUE emita el Dictamen 1/17 (previsto para inicios de 2019), en donde se resolverá la compatibilidad de la Corte de Inversiones propuesta en el Acuerdo Económico y Comercial Global negociado entre Canadá y la Unión Europea, con el derecho de la Unión Europea.

Cuarto. El artículo 344 del TFUE cobra gran relevancia a raíz de la decisión en Achmea, por cuanto prohíbe "someter las controversias relativas a la interpretación o aplicación de los Tratados a un procedimiento de solución distinto..." de aquellos establecidos en el derecho de la UE. Esta consecuencia vendría a establecer que no es necesario aplicar el Artículo 59 de la Convención de Viena sobre el Derecho de los Tratados (el cual no había sido aceptado por tribunales arbitrales como derogatorio de los APPIs, por entenderse que las garantías planteadas en estos prestaban una protección mayor a los inversionistas que lo dispuesto por el derecho comunitario) para derogar los APPIs intra-UE, ya que el artículo 344 del TFUE permite obviar esta norma al impedir que se diriman controversias ante instancias ajenas al derecho de la UE. Será necesario esperar para evaluar cómo los tribunales arbitrales tomarán en consideración estos antecedentes para declararse incompetentes de conocer las controversias que se sometan a su conocimiento.

Quinto. Las implicancias que esta decisión tiene para la negociación de futuros regímenes de solución de controversias son diversas. En primer lugar, deberá resguardarse a toda costa la autonomía del derecho de la UE. Para salvaguardar este principio, la institución que eventualmente pudiera surgir de la negociación para el establecimiento de una corte multilateral de inversiones (que se lleva actualmente al alero de la CNUDMI), deberá alternativamente, constituirse como un órgano de la UE, de modo tal que no vulnere su autonomía, o bien, como una institución que conste de las características señaladas en el caso Dorsch Consult precedentemente citado, que le permitan ejercer la facultad dispuesta en el artículo 267 del TFUE. De esta forma, dicho órgano cumplirá con los requisitos necesarios para recurrir al TJUE a fin de ajustar sus decisiones al derecho de la UE.

La sentencia del TJUE en el caso Achmea tiene alcances insospechados fuera del ámbito del derecho de las inversiones. A través de sus conclusiones, fija criterios para determinar aquello que la Comisión Europea entiende como aceptable respecto a la no vulneración de competencias propias de los órganos del sistema legal de la Unión. Como se adelantó, esta decisión permitirá conocer a los negociadores del Acuerdo de Retirada en el contexto del Brexit si se encuentran navegando en aguas prohibidas. 
Implicancias para la solución de controversias inversionista-Estado a raíz de la sentencia del caso Achmea Pablo Nilo Donoso

Respecto de la Corte de Inversiones negociada por la Unión Europea con distintos Estados (Canadá, México, Singapur y Vietnam), será necesario esperar al próximo año para determinar si el barco logró llegar a su destino o si el TJUE lo hundió por violar su autonomía.

\section{Referencias bibliográficas}

ALSCHNER, Wolfgang (2013). "Americanization of the BIT Universe: The Influence of Friendship, Commerce and Navigation (FCN) Treaties on Modern Investment Treaty Law". Goettingen Journal of International Law, 5 (2).

ANKERSMIT, Laurens (2016). "Belgium Requests an Opinion on Investment Court System in CETA”. Elni Review, 2.

BINDER C., y J.A. Hofbauer (2017) “The Perception of the EU Legal Order in International Law: An In- and Outside View”. In: Bungenberg M., M. Krajewski, C. Tams, J. Terhechte, A. Ziegler (eds). European Yearbook of International Economic Law (2017). Springer, Cham, vol 8: 139203.

DAHLQUIST, Joel (2018) "Spain challenges Novenergia arbitral award in Swedish court, relying on the Achmea judgment", en: https://aquiescencia.net/2018/05/23/spain-challengesnovenergia-arbitral-award-in-swedish-court-relying-on-the-achmea-judgment/ [consulta 13.08.2018]

Hallward-DriemeIER, Mary (2003). "Do Bilateral Investment Treaties Attract Foreign Direct Investment? Only a Bit ... and They Could Bite", en The World Bank Development Research Group Investment Climate. Policy Research Working Paper 3121.

Hobér, Kaj (2015). "Investment Treaty Arbitration and Its Future -- If Any". Arbitration Law Review. Yearbook on Arbitration and Mediation, 7 (8).

IACOB, Iuliana-Gabriela, y Ramona-Elisabeta Cirling (2016). "The Energy Charter Treaty and settlement of disputes - current challenges". Juridical Tribune, 6 (1): 71-83. Disponible en: http:/ /oaji.net/articles/2017/5275-1516538393.pdf [consulta 16.08.2018]

CIEL (2018). Implications of Achmea. How the Achmea Judgment Impacts Investment Agreements with Non-EU Countries. Disponible en: http://www.ciel.org/wpcontent/uploads/2018/04/Implications-of-Achmea.pdf [consulta 12.07.2018] 
LEIKIN, Eric y Martina Magnarelli (2017), "The Future of Intra-EU ECT Claims in the Face of EC Opposition: Boom or Bust?”. Kluwer Arbitration Blog. Disponible en http://arbitrationblog.kluwerarbitration.com/2017/09/15/icca-2/ [consulta 16.08.2018]

LEJOUR, Arlan y María Salfi (2015). "The Regional Impact of Bilateral Investment Treaties on Foreign Direct Investment”. CPB Netherlands Bureau for Economic Policy Analysis. Disponible en: https://www.cpb.nl/sites/default/files/publicaties/download/cpb-discussion-paper-298regional-impact-bilateral-investment-treaties-foreign-direct-investment.pdf [consulta 12.07.2018]

MATEI, Emanuela (2015). "Putting the cart before the horse: a doomed constitutional strategy for negotiating the T-TIP”. Disponible en: http://eulawanalysis.blogspot.com/2015/08/ [consulta 20.08.2018]

OLIVET, Cecilia (2013). "A test for European solidarity. The case of intra-EU Bilateral Investment Treaties". Transnational Institute. Disponible en https://www.tni.org/es/node/1567 [consulta 12.07.2018]

ST. John, Taylor (2018). The Rise of Investor-State Arbitration: Politics, Law, and Unintended Consequences. Oxford University Press.

VoON, Tania y Andrew Mitchell (2017). "Ending International Investment Agreements: Russia's Withdrawal from Participation in the Energy Charter Treaty". AJIL Unbound, 111, 461-466. doi:10.1017/aju.2017.103.

\section{Comunicaciones/ Comunicados de Prensa/ Noticias}

Commission asks Member States to terminate their intra-EU bilateral investment treaties, 18 de junio de 2015. Disponible en http://europa.eu/rapid/press-release_IP-15-5198_en.pdf [consulta 27.08.2018]

Commission communication on the protection of investments, 19 de julio de 2018. Disponible en https://ec.europa.eu/info/publications/180719-communication-capital-movements_en [consulta 27.08.2018]

Comisión Europea - Hoja informativa Paquete de septiembre de procedimientos por incumplimiento: principales decisiones. 29.09.2016. Ver: http://europa.eu/rapid/pressrelease_MEMO-16-3125_es.htm?locale=EN [consulta 26.08.2018] 
Implicancias para la solución de controversias inversionista-Estado a raíz de la sentencia del caso Achmea Pablo Nilo Donoso

El Gobierno cifra en 7.565 millones la cuantía de los arbitrajes por los recortes a las renovables. Disponible en: https://www.eldiario.es/economia/Gobierno-millones-arbitrajesrecortes-renovables_0_705880371.html [consulta 12.07.2018]

Tribunal de Suecia suspende la ejecución del laudo de NovEnergia contra España por recorte a las renovables. Disponible en: http://www.europapress.es/economia/energia-00341/noticiatribunal-suecia-suspende-ejecucion-laudo-novenergia-contra-espana-recorte-renovables20180517195808.html [consulta 12.07.2018] 